\title{
Interannual to Decadal Variability in the Tropical Atlantic
}

\author{
Dietmar Dommenget and Mojib LAtif \\ Max-Planck-Institut für Meteorologie, Hamburg, Germany
}

(Manuscript received 23 March 1998, in final form 30 April 1999)

\begin{abstract}
Analyses of annual mean sea surface temperatures (SST) from observations for the period 1903-94 and four different general circulation models (GCMs) were conducted. The two dominant EOFs of all datasets are characterized by two patterns, which are centered in the trade wind zones, at roughly $15^{\circ} \mathrm{N}$ and $15^{\circ} \mathrm{S}$, respectively. The two patterns are uncorrelated at any lag and the time spectra of the corresponding principle components are consistent with red noise. The SST variability is strongly correlated with wind stress anomalies in the trade wind zones. The correlations between the wind stress and the SST, as well as the correlation between the net heat flux and the SST anomalies are consistent with the assumption that the variability of the upper tropical Atlantic Ocean is forced by the atmosphere. Dynamic feedbacks of the tropical Atlantic Ocean are less important. The variability in the trade wind zones shows a weak correlation with the ENSO mode in the tropical Pacific.
\end{abstract}

\section{Introduction}

Although the database of SST in the tropical Atlantic is as good or better than in the tropical Pacific, the variability of the SST in the tropical Atlantic is not as well understood as in the tropical Pacific. This might be due to the fact that in the tropical Atlantic the variability of the SST is weaker than in the Pacific. The latter is dominated by the El Nino-Southern Oscillation (ENSO) phenomenon. Although ENSO originates in the tropical Pacific, it affects the global climate. The physical mechanisms responsible for ENSO are well understood and ENSO forecast models have predictive skill up to approximately one year in advance.

The same physical mechanism that produces the ENSO mode in the Pacific can also produce an ENSOlike mode in the Atlantic, but due to the different basin geometry it is expected to be much weaker than in the Pacific (Zebiak 1993; Huang et al. 1995; Latif et al. 1996).

Analyses of rainfall data over northeast Brazil (Moura and Shukla 1981), a region that frequently experiences drought conditions, suggested that an interhemispheric dipole in the tropical Atlantic SST anomalies has a major impact on the rainfall in this region. The rainfall is strongly related to the position of the intertropical convergence zone (ITCZ) in the early boreal spring, which in turn may be related to anomalous SST patterns.

Corresponding author address: Dr. Dietmar Dommenget, MaxPlanck-Institut für Meteorologie, Bundestrasse 55, D-20146 Hamburg, Germany.

E-mail: dommenget@dkrz.de
Several EOF analyses of SST anomalies based on monthly or annual mean data found the interhemispheric dipole as one of the first two EOFs. Houghton and Tourre (1991) analyzed an SST dataset of the tropical Atlantic for the period 1964-88 and found that the second EOF is associated with an interhemispheric dipole. However, a rotation of the first five EOFs reveals that the variability in the Northern and Southern Hemispheres cannot be characterized by a dipole. The anomalies north and south of the ITCZ are not significantly correlated with each other in this time interval (Houghton and Tourre 1992).

This is confirmed by the analyses of Enfield and Mayer (1997), who analyzed a record of SST for the period 1950-92. They also analyzed the correlation between the tropical Atlantic SST anomalies and ENSO indices and found that the Atlantic is significantly correlated with ENSO in the region $10^{\circ}-20^{\circ} \mathrm{N}$ with a time lag of about 4-5 months.

Mehta and Delworth (1995) analyzed observed box averaged SST anomalies in the tropical Atlantic in both a 100 -yr dataset and a $100-y r$ simulation with a global general circulation model. They found two timescales of variability that significantly stand out above the background red noise. One type of variability with a timescale of approximately 8-11 yr is characterized by independent variability to the north and south of the equator. The other type of variability has a timescale of approximately 12-20 yr and consists of a dipole. However, Mehta (1998) found in a later study, by performing a reanalysis of the $100 \mathrm{yr}$ of SST observation of the tropical Atlantic, that there is no cross-equatorial dipole mode at any timescale in the tropical Atlantic. 
Chang et al. (1997) studied the relationship between SST, wind stress, and net heat flux anomalies for this region. Additionally, they used a coupled ocean-atmosphere model to examine the role of local air-sea interactions. They indentified that the tropical SST dipole can be attributed to an unstable thermodynamic ocean-atmosphere interaction. They found a realistic parameter regime with a self-sustained interdecadal oscillation of an interhemispheric dipole pattern. The oscillation can be described as follows: Suppose the northern tropical Atlantic exhibits a positive SST anomaly and that the southern tropical Atlantic a negative one. Then, the wind stress in the north will be weakened and that in the south strengthened. The resulting surface heat flux anomalies in both poles will reinforce the initial SST anomalies, which is a positive air-sea interaction feedback. The meridional advection of heat anomalies by the steady ocean currents will act as a negative feedback in both poles. Together the positive and negative feedbacks give rise to a self-sustained interdecadal oscillation. Results from forecasts experiments with the same coupled ocean-atmosphere models show predictability skill for several years ahead (Chang et al. 1997).

In a recent study Penland and Matrosova (1998) analyzed the predictability of tropical Atlantic SST anomalies by linear inverse modeling of observed SSTs. They found that the 6-month influence function in the northern and southern tropical Atlantic tends to be of the opposite sign and evolve into a clear dipole when the analysis is confined to the tropical Atlantic only.

However, the existence of a distinct timescale or the existence of the dipole as a dominant mode of SST variability is still controversial. The observations of tropical Atlantic SST are limited in quality and, in particular, in length. Therefore, it is questionable whether the existence of a decadal ocean-atmosphere interhemispheric dipole mode can be proven simply by analyzing SST observations. For a better understanding of the processes that produce the observed SST anomalies, other quantities such as net heat flux, wind stress, and subsurface temperatures may be useful, but measurements of these quantities are rare in space and time, and are limited in quality.

Simulations with coupled general circulation models (CGCMs) may provide additional insights into the dynamics of the SST variability in the tropical Atlantic. Although the CGCMs do not model the climate system correctly in all respects, they have the advantage of providing all important quantities without spatial and temporal gaps and with equal quality. Our study is mainly based on empirical orthogonal function (EOF) analyses of the observed SST anomalies and those simulated by four different CGCMs. It will be shown that the tropical Atlantic is dominated by SST variability, which is centered in the northern and southern trade wind zones. Furthermore, it will be shown that the centers in the northern and the southern trade wind zones are mainly independent of each other, and that, therefore, an interhemispheric dipole does not exist for timescales less than 25 yr. A combined analysis of the SST, wind stress, and the net heat flux anomalies indicates that the variability in the tropical Atlantic is induced by atmospheric forcing and that dynamic feedbacks of the ocean are less important. We performed additional experiments with an atmospheric general circulation model (AGCM) forced by prescribed SST anomalies and coupled to a slab ocean model. The results of these experiments support the results of the CGCM simulations and those obtained from the SST observations.

The paper is organized as follows. The results of the analyses of the observed SSTs are presented in section 2. We describe the results of the CGCMs simulations in section 3. The role of the surface heat flux is discussed in section 4. We present the result of the AGCM slab ocean simulation in section 5 . The forced experiments with our AGCM are described in section 6, while the paper is concluded with a discussion of our main findings in section 7 .

\section{The GISST observations}

The following analyses are based on the Global Sea Ice and Sea Surface Temperature dataset (GISST) that provides monthly mean SSTs for the period 1903-94 (Parker et al. 1995). The data were interpolated onto a $2.8125^{\circ} \times 2.8125^{\circ}$ grid. We restrict ourselves to the tropical Atlantic from $30^{\circ} \mathrm{S}$ to $30^{\circ} \mathrm{N}$. The monthly data were averaged to obtain annual mean data, and at each grid point the local linear trend was subtracted.

The statistically dominant SST patterns in the tropical Atlantic can be determined by EOF analyses. Figure 1 shows the first two EOFs of the GISST observations explaining $33.8 \%$ and $22.2 \%$ variance of the SST variability, respectively, in the examined region. Throughout this paper presented EOF patterns have been normalized, so that the principle components (PCs) of the EOF patterns have a standard deviation of 1.0. EOF-1 is characterized by a uniform pattern with maximum values near the eastern boundary. EOF-2 is characterized by a north-south dipole, with centers of action in the region of the trade wind zones. The third and fourth EOFs (not shown) have maximum variability at the northern $\left(30^{\circ} \mathrm{N}\right)$ and southern edges $\left(30^{\circ} \mathrm{S}\right)$ of the examined region; they explain only a few percent of the variability in the tropical Atlantic and are of minor interest.

Figure 2 shows the spectra of the corresponding principle components PC-1 and PC-2. The spectra of the PCs are tested against the hypothesis that the spectra are produced by a first-order autoregressive process (red noise spectra), and a 95\% confidence level for accepting the red noise hypothesis is also shown. This hypothesis was introduced by the stochastic climate model of Hasselmann (1976). The spectra are in good agreement with the red noise assumption, but they have a slightly sig- 
a) EOF-1 exp. variance $=33.77 \%$

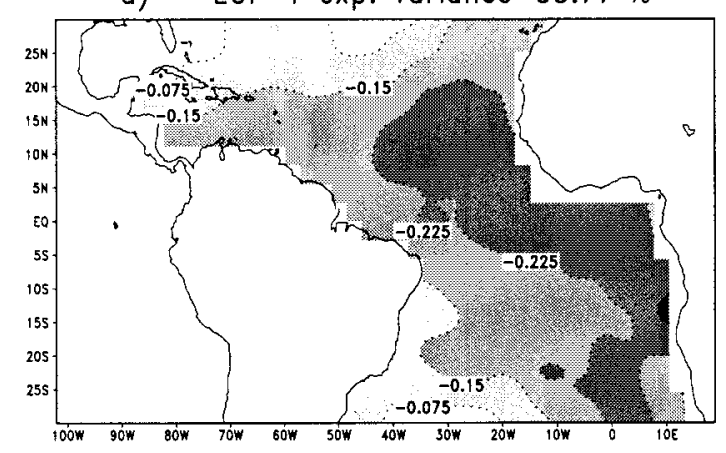

b) EOF-2 exp. variance $=22.22 \%$

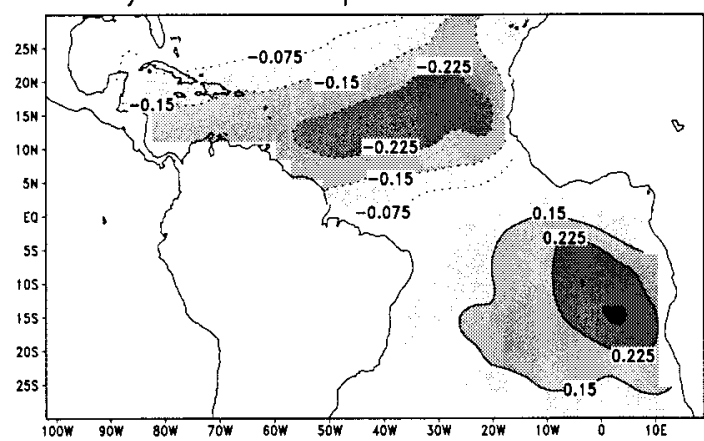

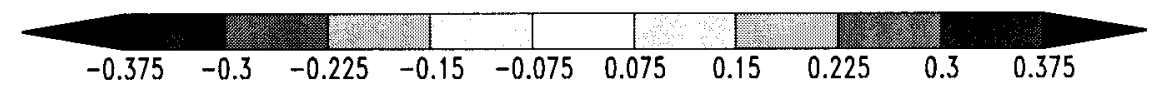

c) EOF-1 explained variance

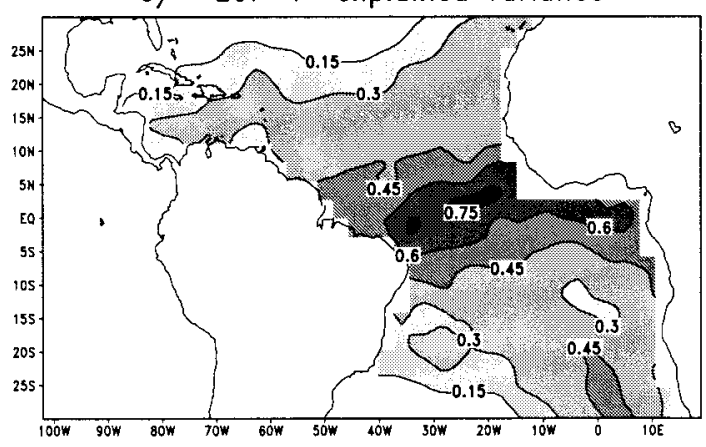

d) EOF-2 explained variance

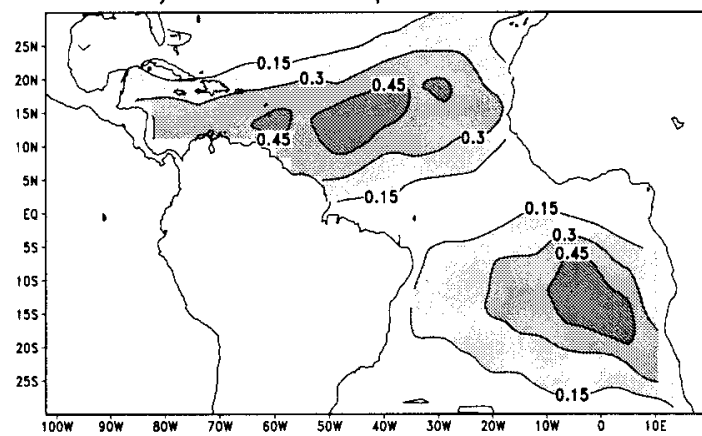

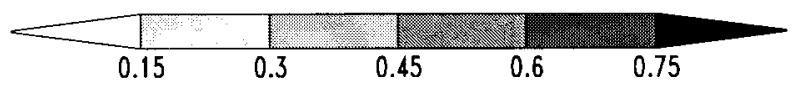

FIG. 1. (a) Leading EOFs of the GISST observations, explaining about $34 \%$ of the variance. (b) Second most energetic EOF, explaining about $22 \%$ of the variance. (c) and (d) Spatial distribution of the explained variance for EOF-1 and EOF-2, respectively.

EOF-1

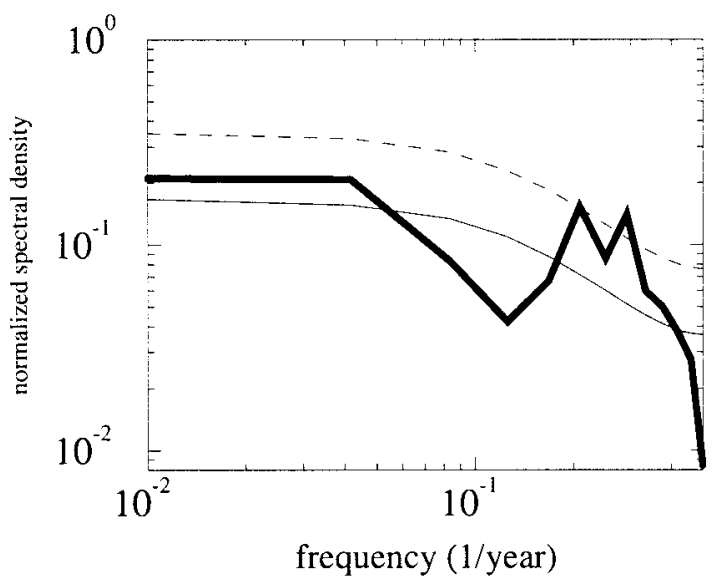

EOF-2

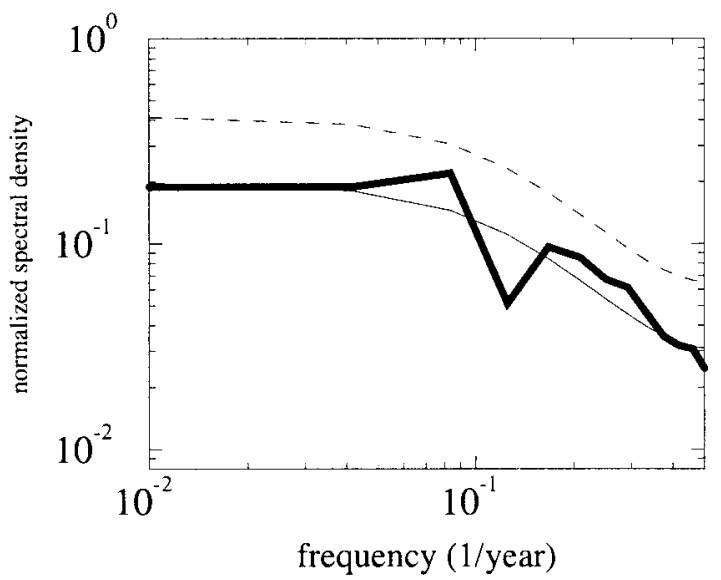

FIG. 2. Spectra of PC-1 and PC-2 corresponding to EOF-1 and EOF-2 in Fig. 1. The thin solid lines are the expected red noise spectra calculated as described in the text. The dashed lines are the 95\% confidence level for the null hypothesis of a red noise spectra. 

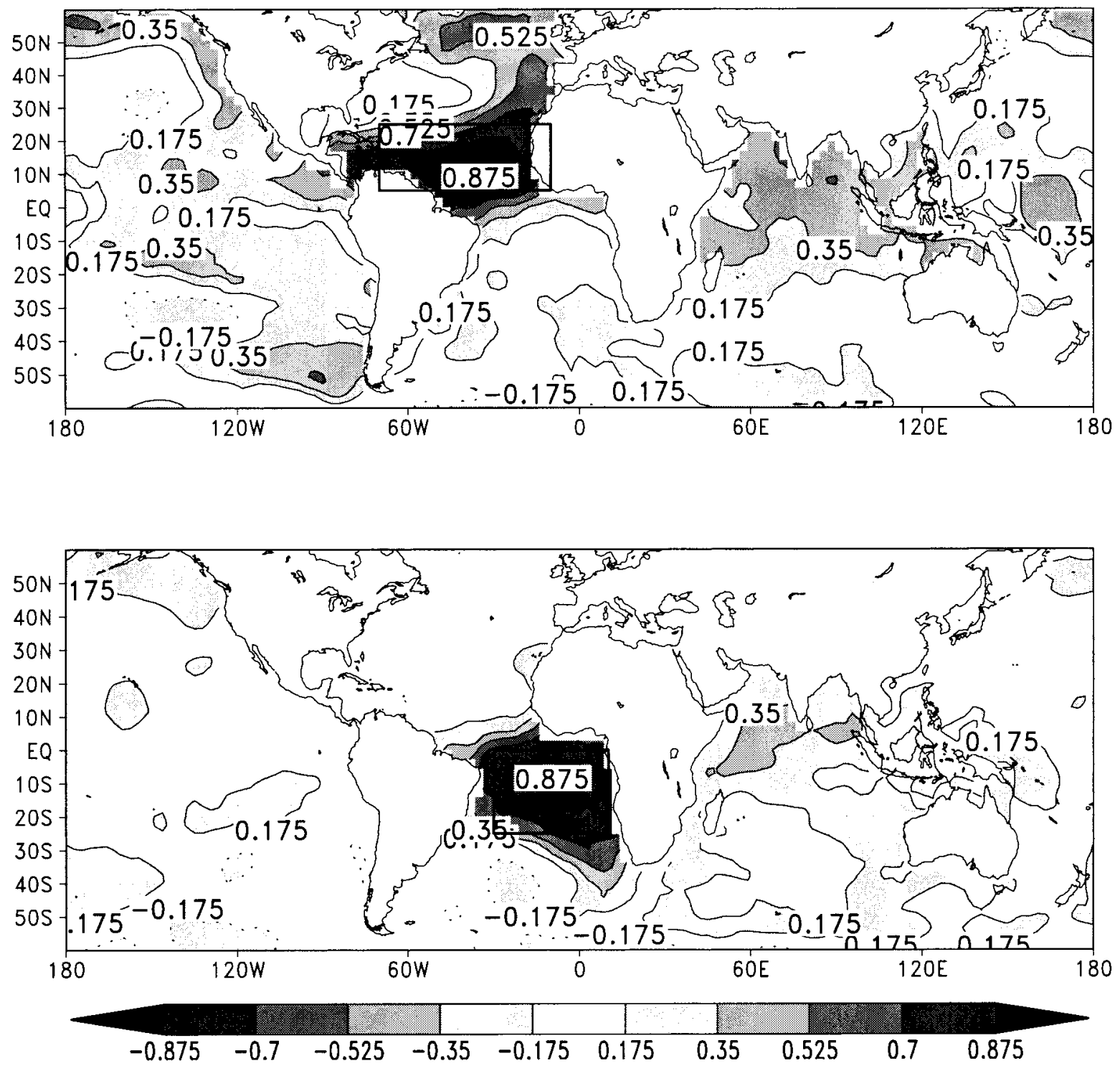

FIG. 3. Correlation of box averaged SST anomalies with near-global SST anomalies. Shaded areas are significantly nonzero correlations at the $95 \%$ confidence level.

nificant increase of variability for periods of $3-5 \mathrm{yr}$ for the PC-1.

As we shall show in the following, the SST anomalies in the regions of the maximum trade winds cannot be explained by one single EOF pattern, but they have to be regarded as a linear combination of the two leading EOFs. The pattern of the EOF-2 alone could lead to the conclusion that variations north of the equator are anticorrelated with those south of the equator. This, however, is not the case.

The correlations of the near-global SST anomalies with box averaged SST anomalies north and south of the equator are shown in Fig. 3. The box north of the equator shows significant correlations with SSTs at higher latitudes of the Atlantic, but it has no significant correlation or anticorrelation with the south Atlantic. The box south of the equator also shows a relatively local correlation pattern in the Southern Hemisphere of the Atlantic. Both correlation maps lead to the conclusion that the SST anomalies in the northern and southern trade wind zones of the Atlantic are not significantly correlated with each other. Lag correlations of the two box averaged time series do not show either significant correlations for lags shorter than $10 \mathrm{yr}$.

The two boxes in the tropical Atlantic are significantly correlated with the SST anomalies outside the Atlantic. The northern box is significantly correlated with the eastern Pacific and Indian Oceans. The southern box has generally smaller correlations with SST anomalies outside the Atlantic, but it exhibits significant correlations 

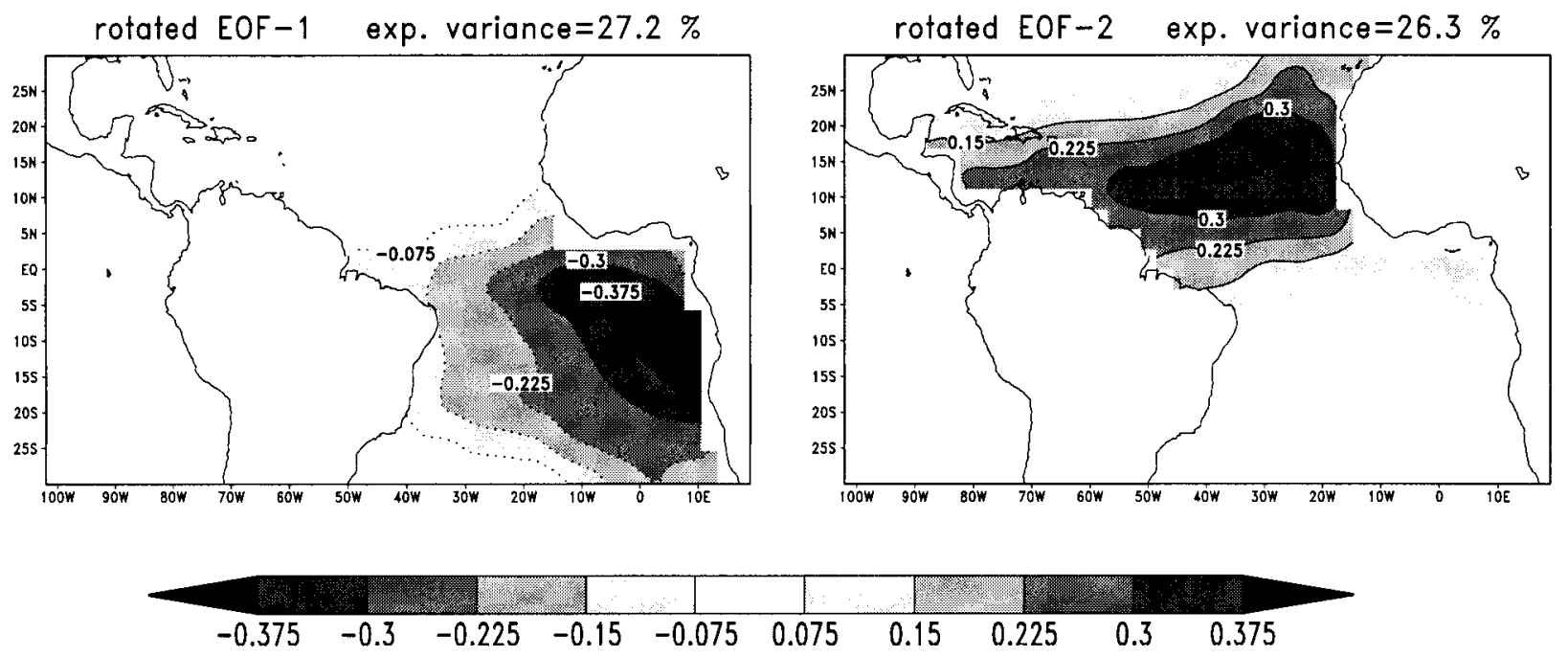

FIG. 4. VARIMAX rotated EOF-1 and -2 of the SST of the GISST observations. Contours and shading as in Fig. 1.

in essentially the same regions as the northern box. Most of the teleconnections are probably due to the ENSO phenomenon. An exception is the correlation of the northern tropical box with the SST anomalies in the northern Atlantic, which indicates that the variability seen these two regions is related. This issue, however, will be discussed elsewhere.

Although the EOF-2 of the tropical Atlantic SST anomalies is a dipole pattern, the SST anomalies in the two hemispheres of the tropical Atlantic are not anticorrelated with each other. As indicated by the correlation patterns in Fig. 3, it is likely that the variability in the tropical Atlantic is dominated by two spatially separated patterns.

A basis of a vector space can always be transformed into a different basis by an orthogonal rotation of the basis vectors. Rotations of EOFs are useful when two or more EOFs are statistically degenerated, which means that the EOFs explain equal amounts of variability over the region examined (North et al. 1982) or when another criterion for the orthogonalization is considered (Richman 1986). The two leading EOFs in the analyses presented above have comparable amounts of explained variances, but they are not statistically degenerated. Therefore, EOF-1 has to be regarded as the most dominant pattern in the tropical region. Nevertheless, the two EOFs have comparable amounts of variability over large regions. Therefore, it can be interesting to study rotated EOFs.

In addition to an ordinary EOF analysis, a rotated EOF analysis can give a second set of orthogonal basis vectors. One useful criterion for this analyses is the VARIMAX criterion (Kaiser 1958; Kaiser 1959; Richman 1986). The VARIMAX method for rotating EOFs leads to the orthogonal rotation with the highest possible localization of the SST pattern. In other words, if an ordinary EOF analysis distributes the variability of one region into different EOF patterns, as into EOF-1 and -2 of our analysis of the tropical Atlantic, the VARIMAX method finds the rotation in which the variability of that region is concentrated in one pattern as much as possible.

Applying the VARIMAX method we computed 10 rotated EOFs. They were obtained by an orthogonal rotation of the 10 leading EOFs. The stability of the two dominant pattern has not been found to be influenced by the number of EOFs chosen, even if only the first two EOFs were used for the rotation. The two leading rotated EOFs are shown in Fig. 4. The patterns of the two leading rotated EOFs are spatially well separated and are almost equal to the two patterns obtained by the box correlation analysis shown in Fig. 3. The time series of the northern box has a correlation of 0.99 with the PC of the leading rotated EOF and the southern box has a correlation of 0.98 with the PC of the second rotated EOF. Figure 5 shows the spectra of the PCs of the two leading rotated EOFs and the lag correlation between the two PCs. The spectra are consistent with a red noise spectra, although both spectra show marginally significant increases in the variability at periods of 3-5 yr. Furthermore, the two PCs are not significantly correlated for lags up to $9 \mathrm{yr}$.

The rotation of the 10 leading EOFs shows that a major part of the SST variability can be explained by two spatially separated and uncorrelated patterns. The patterns are centered in the northern and southern trade wind zones of the tropical Atlantic. A similar result has been obtained by Houghton and Tourre for a shorter SST dataset (Houghton and Tourre 1992).

The question as to whether the two EOFs are degenerated statistically is not important for the SST variability in the tropical Atlantic. The fact that the two leading EOFs can be represented as two spatially wellseparated patterns with orthogonal time evolution is 
NORTH

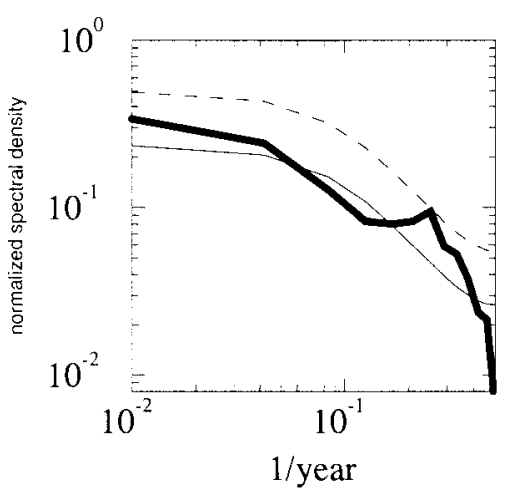

SOUTH

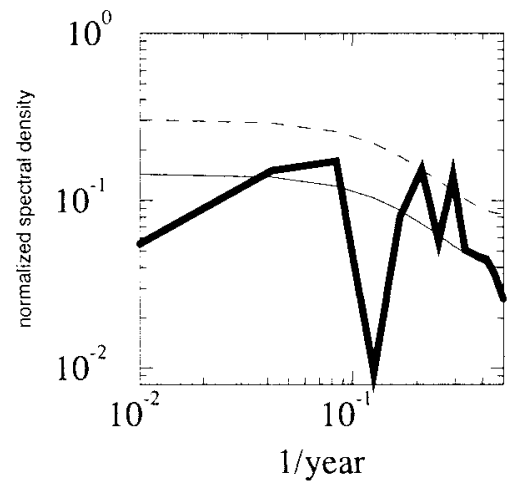

Correlation NORTH with SOUTH-PATTERN

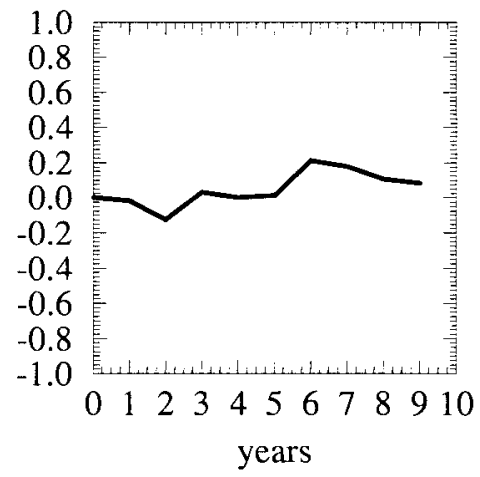

FIG. 5. Spectra of the rotated EOF-1 and -2 shown in Fig. 4. Thin lines and dash lines in the spectra plots as in Fig. 2. The right plot shows the correlation between the rotated EOF-1 and -2 in subjection of the lag in time, while the northern patterns lags the southern.

more important physically. Suppose that the EOF-1 is separated statistically from EOF-2, which is almost the case in the GISST dataset; then the two spatially separated patterns of the rotation are not a possible EOF system, but they are still a orthogonal base that can be used to describe the SST variability in the tropical Atlantic. Therefore, the dominance of the EOF-1 can be understood as a weak interaction between the two rotated patterns, which leads to the preferential EOF system shown in Fig. 1.

From a mathematical point of view the two representations of the SST variability are equivalent, but it has to be considered that, from a physical point of view, the different representations of the SST anomalies may lead to different explanations of the underlying physical mechanisms. For example, in the representation of the SST variability based on the two ordinary EOF patterns, the SST anomalies are created by an equatorial mode and an orthogonal (independent) dipole mode, which explain comparable amounts of variability in the same regions. This may lead to the wrong conclusion that the tropical Atlantic SST variability is dominated by a dipole pattern. However, we have shown that the two poles are not significantly anticorrelated with each other. Therefore, the patterns of the first two ordinary EOFs are not the best basis on which to explain the SST anomalies in the tropical Atlantic.

In the rotated representation the leading ordinary EOF, which has its maximum at the thermal equator, is a superposition of the two leading rotated EOFs. Therefore, there is no real dominant equatorial pattern in the tropical Atlantic comparable to the one found in the tropical Pacific, which is connected to the ENSO mode. In the following, the SST anomalies in the tropical Atlantic will be represented by rotated EOFs only.

\section{The CGCM simulations}

To examine interannual to decadal variability, a time series of $90 \mathrm{yr}$ may be too short, as we have seen above.
It could not be shown rigorously that the SST variability in the northern and southern trade wind zones are independent of each other. Therefore, we analyzed additionally the outputs of simulations with CGCMs.

Although the GCMs do not model the climate system correctly in all features, they have the advantage of providing all important quantities without spatial and temporal gaps and with equal quality. It is possible, for instance, to analyze not only SST anomalies, but also the surface heat flux and surface wind stress anomalies that may produce them.

We analyzed the outputs of four different CGCMs. The CGCMs were developed jointly at the Max-PlanckInstitut für Meteorologie and the Deutsches Klimarechenzentrum, and one model was developed at the Geophysical Fluid Dynamics Laboratory (GFDL). A list of the models is given in Table 1. The simulations differ in length, and the resolutions of the models are also quite different. Thus, the analyzed CGCMs cover a large part of the parameter space. For more detailed description of the CGCM refer to the following publications. For the ECHAM3-LSG CGCM see Maier-Reimer et al. (1993), Roeckner et al. (1992), and Voss et al. (1998). The ECHAM4-HOPE2 CGCM is described in Frey et al. (1997). For the ECHAM4-OPCY CGCM experiment see Bacher et al. (1998) and Roeckner et al. (1996). The CGCM of the GFDL is described in Manabe et al. (1991).

For all four CGCMs the same analyses, as performed for the GISST data, were conducted. Figure 6 shows the two leading VARIMAX rotated EOFs of each of the four different CGCMs. On the left-hand side are shown the EOF with maximum in the northern trade wind zone are and on the right-hand side the EOF (rotated pattern) with maximum in the southern trade wind zone.

For the ECHAM4-HOPE2, the ECHAM3-LSG, and the ECHAM4-OPYC CGCM simulations, the differences between the two leading ordinary EOFs (not shown) and the two leading rotated EOFs are negligible. 
TABLE 1. List of CGCMs used in this study.

\begin{tabular}{llcc}
\hline \hline \multicolumn{1}{c}{ CGCM } & Time resolution & Number of & years \\
\hline ECHAM4-HOPE2 & Annual mean, detrended & 118 & Spatial resolution \\
ECHAM4-OPYC & Annual mean, detrended & 240 & $2.8125^{\circ} \times 2.8125^{\circ} *$ \\
ECHAM3-LSG & Annual mean, detrended & 700 & $2.8125^{\circ} \times 2.8125^{\circ} *$ \\
GFDL-MOM & Annual mean, detrended & 1000 & $5.625^{\circ} \times 5.625^{\circ}$ \\
\hline
\end{tabular}

* The ocean model has a meridional resolution of $0.5^{\circ}$ within the region $10^{\circ} \mathrm{N}-10^{\circ} \mathrm{S}$.

The two leading ordinary EOFs of the GFDL simulation are similar to the two leading ordinary EOFs of the GISST observations (see Fig. 1). However, a rotation of the ordinary EOFs with the VARIMAX criterion finds the spatially separated patterns (shown in Fig. 6).

It is remarkable that all CGCMs show similar variability in the two leading rotated EOFs. Similar to the analysis of the GISST data, the stability of the two dominant patterns of the CGCM simulations does not significantly depend on the number of EOFs chosen for the rotation. In all datasets the two leading rotated EOFs are also found by using only the first two EOFs for the VARIMAX rotation. The amplitudes are at comparable levels and the patterns are very similar in all CGCMs simulations. The spectra of the PCs of the two leading rotated EOFs of the four CGCMs are shown in Fig. 7. None of the spectra of the northern and the southern patterns show any significant differences relative to the expected red noise spectra. We conclude from these analyses of the model simulations that the dominant SST variability in the tropical Atlantic is not linked to a specific timescale. In particular, there is no evidence for enhanced variability at decadal timescales, which was found by several authors (Mehta and Delworth 1995; Chang et al. 1997). Furthermore, we did not find much evidence for the existence of a tropical Atlantic dipole pattern in the CGCM simulations.

The Pacific SST variability is dominated by ENSO, which is an equatorial mode of variability. The dominant SST variability in the tropical Atlantic region is found in the trade wind zones, and there is no dominant equatorial mode. This does not mean that there is no ENSOlike variability in the equatorial region of the Atlantic. Zebiak (1993) and Latif et al. (1996) have shown that an ENSO-like mode exists in the Atlantic. This mode, however, accounts for only a small fraction of the SST variability in the tropical Atlantic, which is reflected in the fact that the two leading rotated EOFs in all datasets are centered in the trade wind zones and not at the equator.

\section{Relationship of the SST anomalies to the wind stress anomalies}

The two leading rotated EOFs of the GISST observations are centred in the region of maximum trade winds. The same result was obtained from the CGCM simulations. Our hypothesis for the generation of the
SST anomalies in the centers of action is the following: changes in the wind field lead to changes in the surface heat flux, which in turn drive the SST anomalies.

Figure 8 shows the correlations between the wind stress vector and the SST in the northern and southern trade wind zones (indicated by the boxes). A correlation of the wind field relative to box averaged SST anomalies and not the SST field itself have been chosen to quantify the local and teleconnection between the wind field and the large-scale SST anomalies in the tropical Atlantic.

The two upper plots show the correlations of observed (Comprehensive Ocean-Atmosphere Data Set) wind stress anomalies with the observed SST anomalies of the GISST dataset during the period 1945-89. The lower plots show similar analyses for the ECHAM3-LSG CGCM. The wind stress anomalies are correlated with the SST anomalies in both trade wind zones. A positive SST anomaly is associated with weakened wind stress in both trade wind zones, or vice versa. This strong correlation between the wind stress and the SST anomalies may be the clue to the SST variability in the tropical Atlantic. If ocean dynamics, such as wave propagation, convection, and advection are of minor importance for the generation of the SST variability in the tropical Atlantic, atmospheric forcing has to be the dominant process for producing SST anomalies. The correlations between the wind stress and the SST anomalies in the tropical Atlantic are consistent with the picture that the ocean responds passively to changes in the atmosphere.

The lag correlations of the net heat flux and the SST anomalies are shown in Fig. 9 as obtained from the ECHAM3-LSG CGCM simulation. When the net heat flux leads the SST anomalies, the correlations inside the trade wind zones is positive, which then acts to build up the SST anomalies. When the SST anomalies lead the net heat flux anomalies the correlation inside the trade wind zones is negative, which will act to restore the mean condition in the SST field. At lag $=$ 0 the correlation of the net heat flux and the SST anomalies in the trade wind zones is still positive in some regions, namely, in the western part of the northern trade wind zone and the northern part of the southern trade wind zone. This may be explained by the wind field itself, which will transport the air to these regions. The fact that the correlation is still positive and not zero indicates that there is a weak positive feedback 
$\mathrm{ECHO} 2$ rot. EOF -2 exp. variance $=17.8 \%$

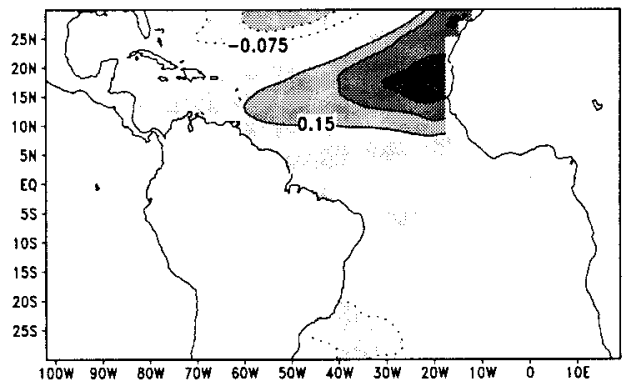

ECHAM 4.OPYC rot. EOF -1 exp. variance $=20.8 \%$

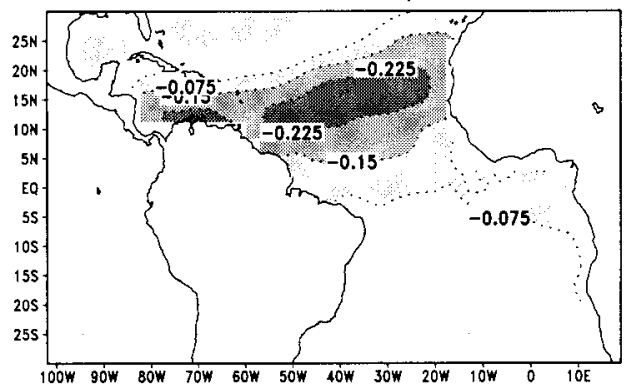

ECHAM3.LSG rot. EOF -2 exp. variance $=17.1 \%$

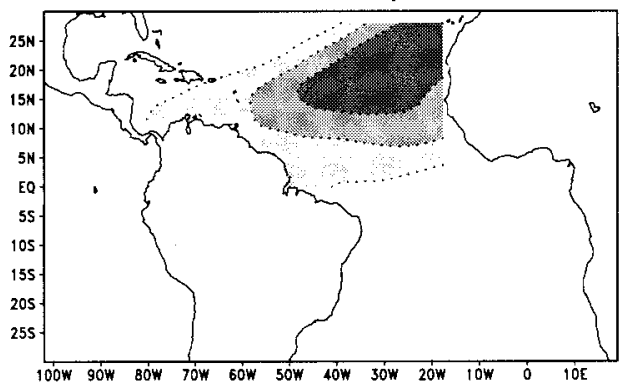

GFDL rot. EOF -2 exp. variance $=10.5 \%$

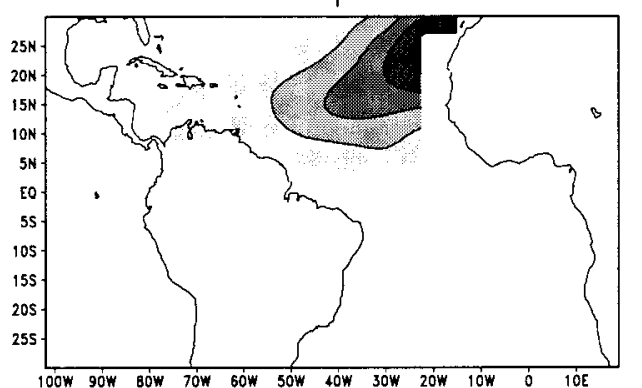

rot. EOF -1 exp. variance $=19.4 \%$

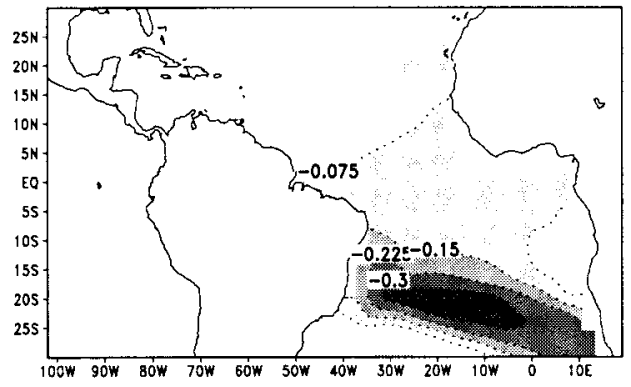

rot. EOF-2 exp. variance $=17.0 \%$

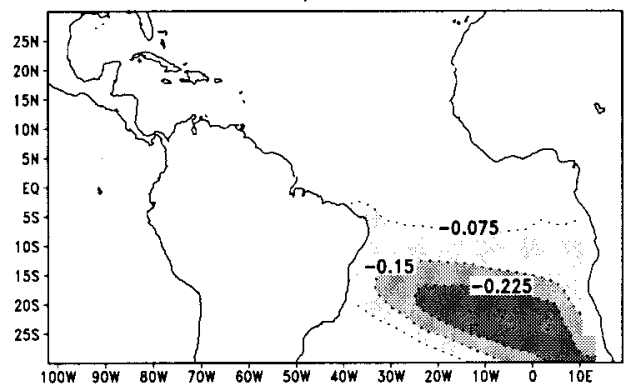

rot. EOF-1 exp. variance $=24.2 \%$

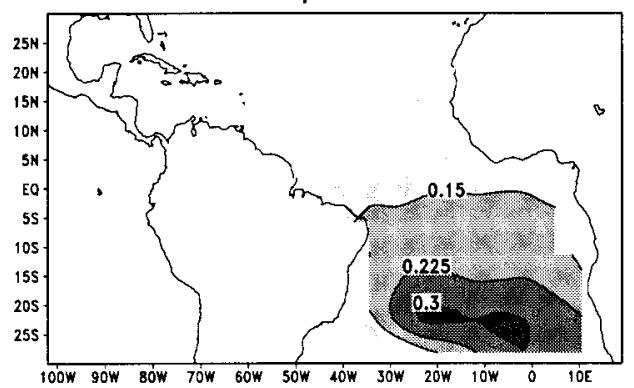

rot. EOF-1 exp. variance $=12.7 \%$

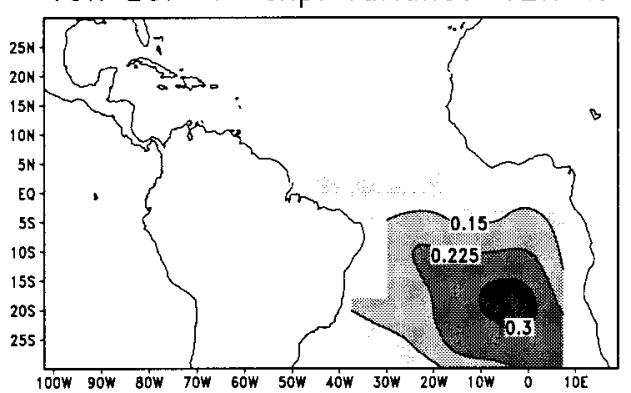

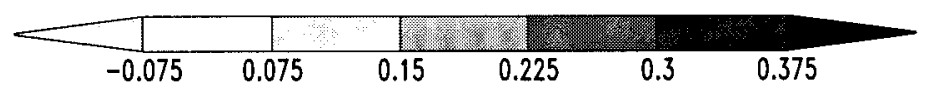

FIG. 6. The two leading rotated EOF of four different GCM simulations. EOF patterns with maxima in the Northern Hemisphere are on the left-hand side and the patterns with maxima in the Southern Hemisphere are on the right-hand side. Contours and shading as in Fig. 1. 

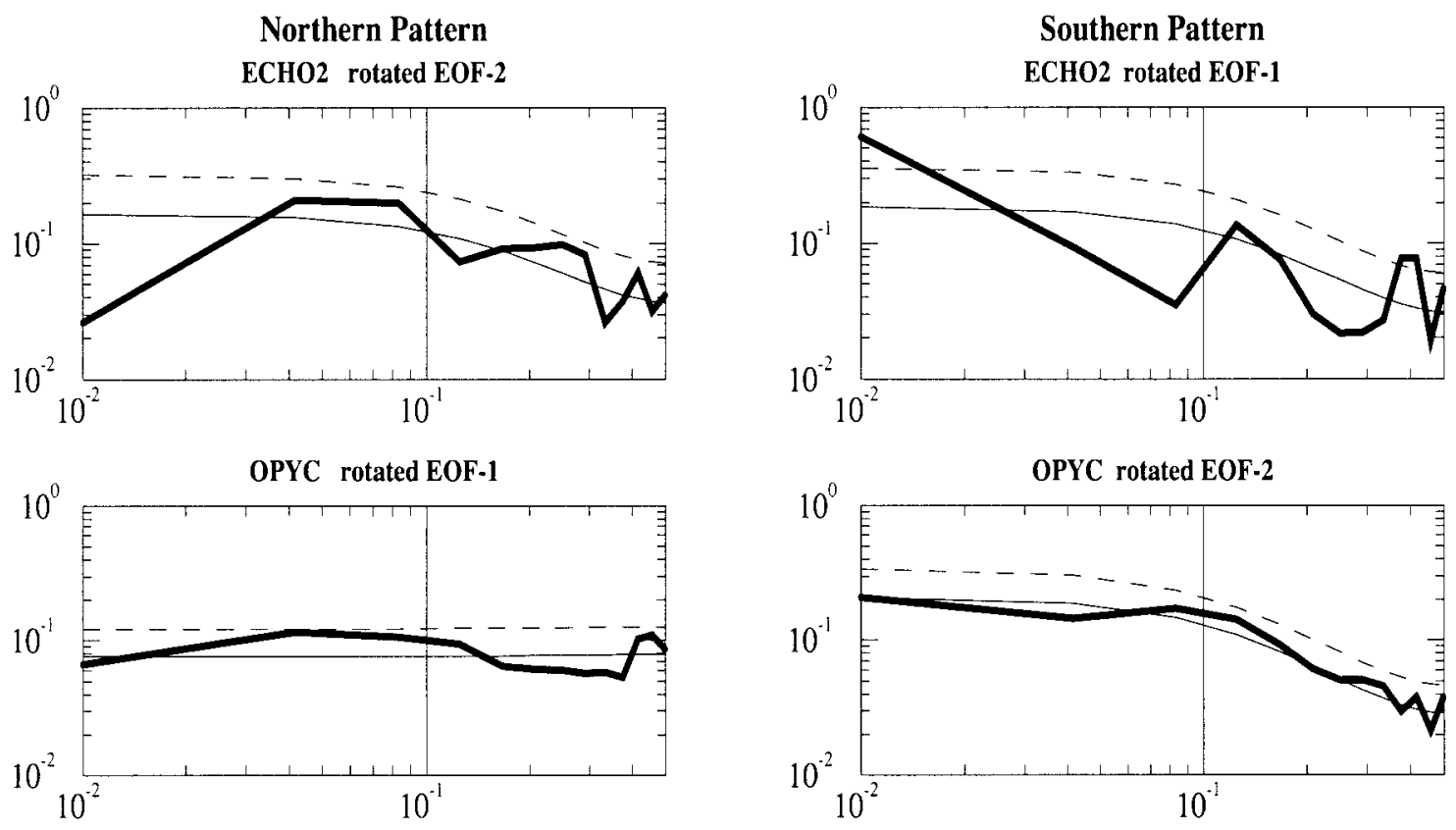

LSG rotated EOF-2
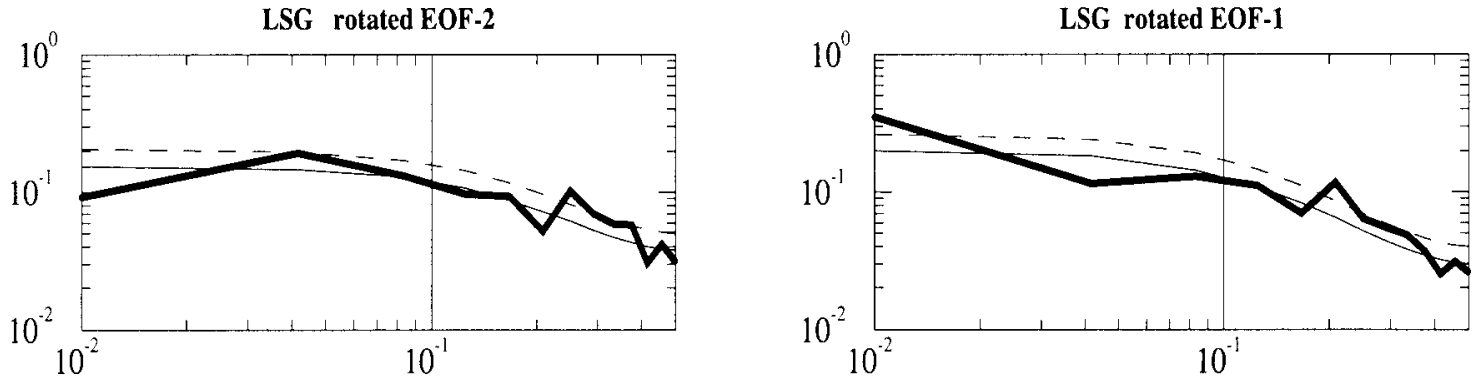

GFDL rotated EOF-1
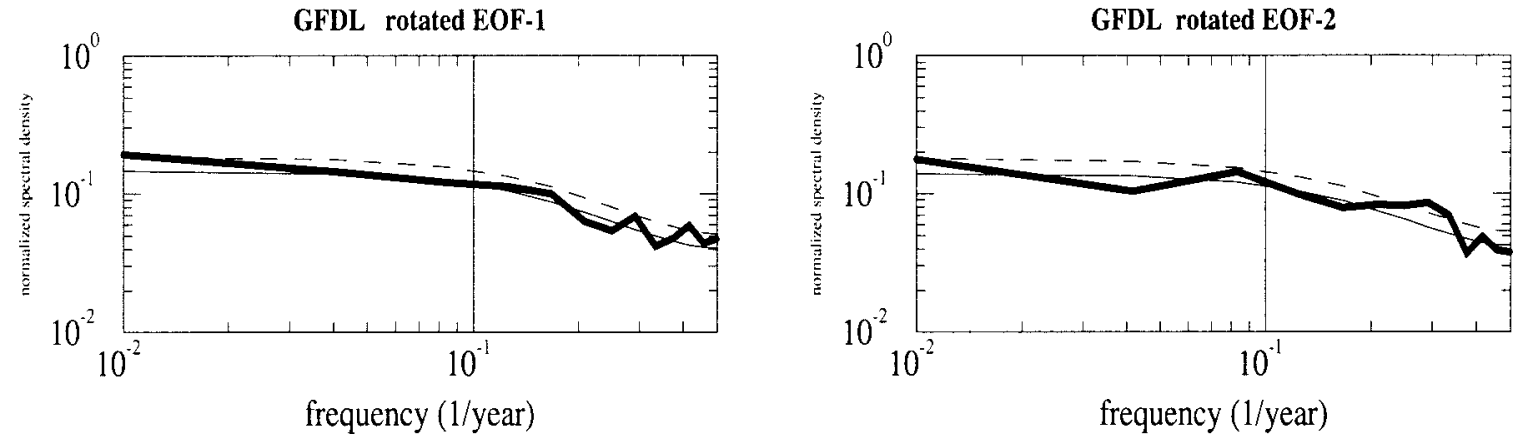

FIG. 7. Spectra of PCs of the two leading rotated EOFs derived from the coupled model simulations. The order of the spectra is equal to Fig. 6 and the thin lines and dashed lines are defined as in Fig. 2.

between the ocean and the atmosphere inside the trade wind zones, which may be the reason why the trade wind zones are the regions of the strongest SST variability. There is no evidence for an interhemispheric connection between the net heat flux and the SST anomalies.

In summary, it is likely that the changes in the wind stress field manifest themselves in variations in the surface heat flux, which will force the SST anomalies, as discussed in Chang et al. (1997).

\section{An ocean mixed layer model}

The results of the analyses of the observations and the CGCM simulations lead to the conclusions that the SST variability in the tropical Atlantic can be explained by atmospheric forcing only, and ocean dynamics are of minor importance. In order to test this hypothesis, we coupled a mixed layer ocean model with the ECHAM3 atmosphere model. The mixed layer model has a constant depth of $50 \mathrm{~m}$ and does not carry (by 

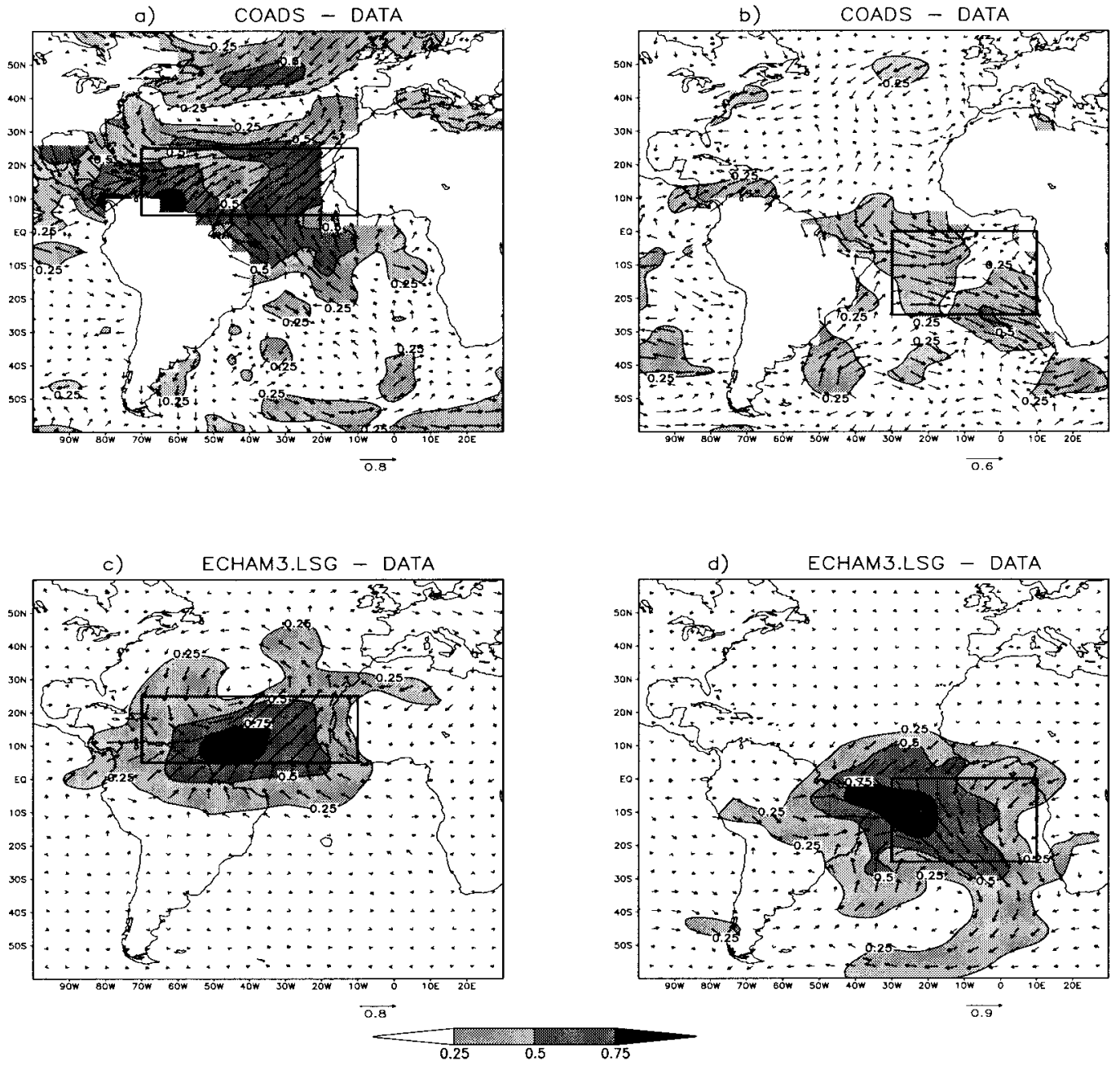

FIG. 8. Upper plots: Correlations between GISST SST anomalies and COADS surface wind stress. (a) Correlation of the SST anomalies in the northern box with the surface wind stress anomalies, (b) correlation of the SST anomalies in the southern box with the surface wind stress anomalies. Lower plots: Correlations between SST anomalies and surface wind stress from the ECHAM3/LSG CGCM simulation. (c) Correlation of the SST anomalies in the northern box with the surface wind stress anomalies, (d) correlation of the SST anomalies in the southern box with the surface wind stress anomalies.

construction) any ocean dynamics. Variations in the heat flux only can produce SST anomalies in such a model. The mixed layer simulation can be compared directly to the ECHAM3-LSG simulation, which employs the same atmosphere model. The simple coupled model has been integrated for $220 \mathrm{yr}$. The years 21-220 were analyzed in the same way that the CGCM simulations and the GISST observations have been analyzed.

The two leading EOFs of the SST variability of the mixed layer simulation are shown in Fig. 10. The patterns of EOF-1 and EOF-2 are similar to that derived from the GISST observations. EOF-1 explains $21.0 \%$ and EOF-2 $16.2 \%$ of the total variability in the examined region. Therefore, the two EOFs are separated significantly. Nevertheless, the VARIMAX rotation of the 10 leading EOFs was applied. The two leading rotated EOFs are shown in the lower plots of Fig. 10. The two leading rotated EOFs are very similar to those obtained from the GISST observations and the CGCM simulations. The spectra of the PCs of the two leading rotated EOFs are shown in Fig. 11. The northern pattern exhibits increased variability for periods from 3 to $7 \mathrm{yr}$, but overall the spectra of the PCs of the two rotated patterns are consistent with red noise processes.

It can be concluded from the results of the mixed layer simulation that the dominant SST variability in the tropical Atlantic is explained by atmospheric forcing only, and dynamic processes in the ocean, such as convection, advection, and wave propagation, are not important in producing the basic spatial structure of the SST variability.

\section{Atmospheric model forced by SST anomalies}

To further investigate the connection between the SST anomalies and the atmospheric response, several sim- 

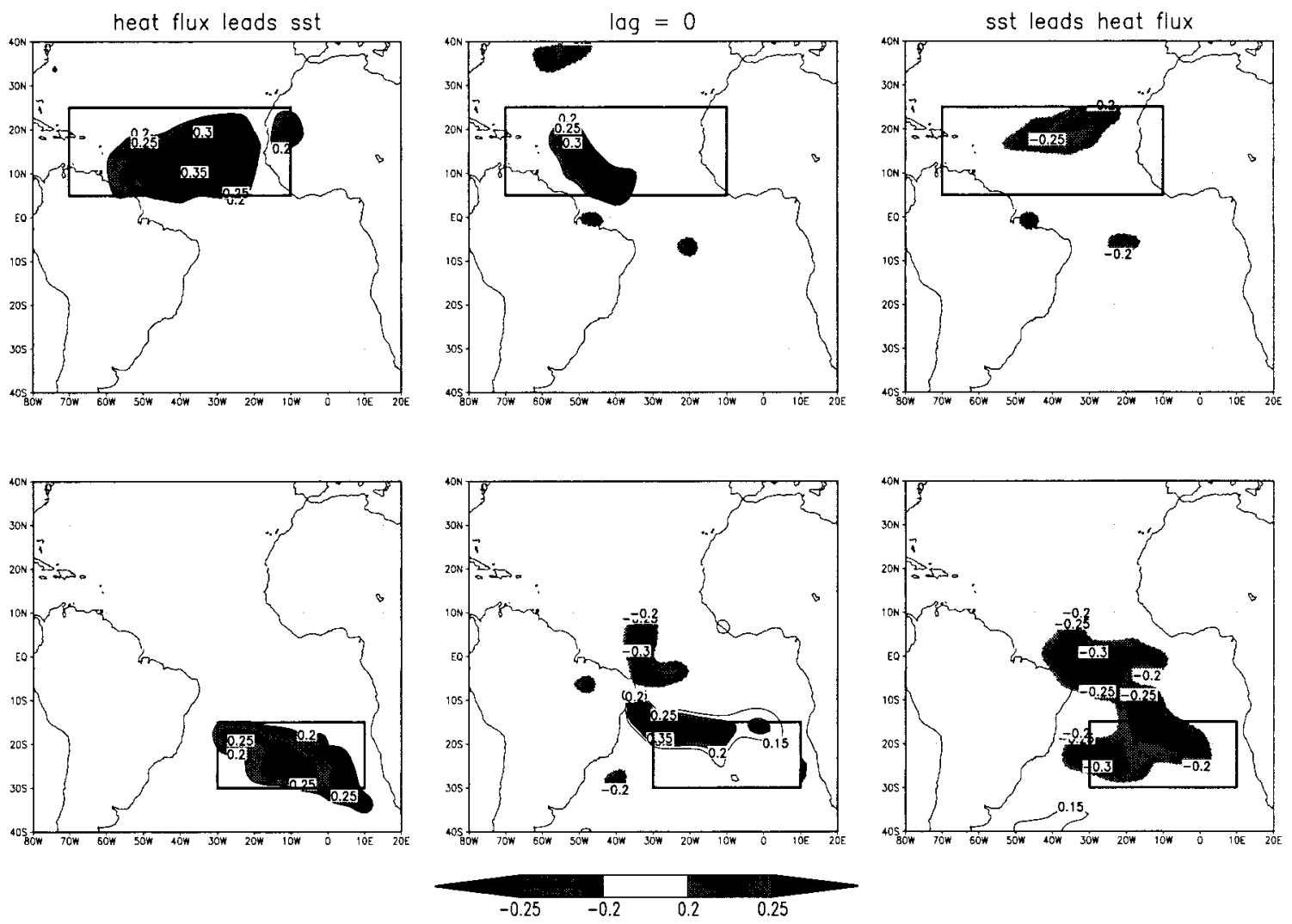

FIG. 9. Lag correlation between net heat flux anomalies and the SST anomalies averaged over the drawn boxes, based on annual mean data from the ECHAM3-LSG simulation.

ulations with the atmospheric circulation model ECHAM3 have been carried out. In these simulations the atmosphere model is forced by different SST anomalies. Five different simulations with different SST forcing have been conducted. A control simulation was integrated for $20 \mathrm{yr}$. It is forced with a climatological SST that was taken from the coupled ocean-atmosphere simulation with the ECHAM3-LSG CGCM. The other four simulations were integrated for $10 \mathrm{yr}$, each with the same SST field plus different constant SST anomaly patterns added. The added SST anomaly patterns are shown in Fig. 12. The SST anomalies are placed in the zones of maximum trade wind. The amplitudes are chosen to be about twice the standard deviation of the SST anomalies in these regions.

The purpose of the simulations is to analyze the effect that different SST anomalies in the trade wind zones have on the state of the atmosphere. Using the results of the simulations it is possible to study whether the response of the atmosphere is local or interhemispheric and whether the atmosphere has the tendency to amplify or damp the SST anomalies.

The results for the change in the wind stress and the net heat flux are shown in Figs. 13 and 14. The plots show the differences of the 10-yr mean values of the response experiments and the $20-\mathrm{yr}$ mean values of the control run divided by the standard deviation of the annual mean values of the $20 \mathrm{yr}$ of the control run. Thus the units are in standard deviations. Following a $t$ test, a change of $1.5 \sigma$ in the mean state over a $10-\mathrm{yr}$ period represents a statistically significant change at the $95 \%$ level.

In the upper left plot the simulation forced by the northern SST pattern is shown, the lower left plot shows the simulation forced by the southern SST pattern, and the upper right plot shows the simulation forced by the dipole (composed of the northern and the negative southern SST anomaly pattern). The difference between the dipole simulation and the sum of the simulations with the northern and the negative southern SST anomaly pattern are shown in the lower right plot. This last plot provides an indication of the linearity of the response. Although the atmospheric model is global, there is no significant change in the wind stress field or the net heat flux outside the tropical Atlantic.

A deviation from the climatological SST results in a local negative feedback through the net heat flux in the center of the SST anomaly (see Fig. 13), while at the western edge of the SST anomaly pattern the net heat flux responses tend to create SST anomalies. In both experiments the response in the net heat flux and that in the wind field is limited to the region close to the 

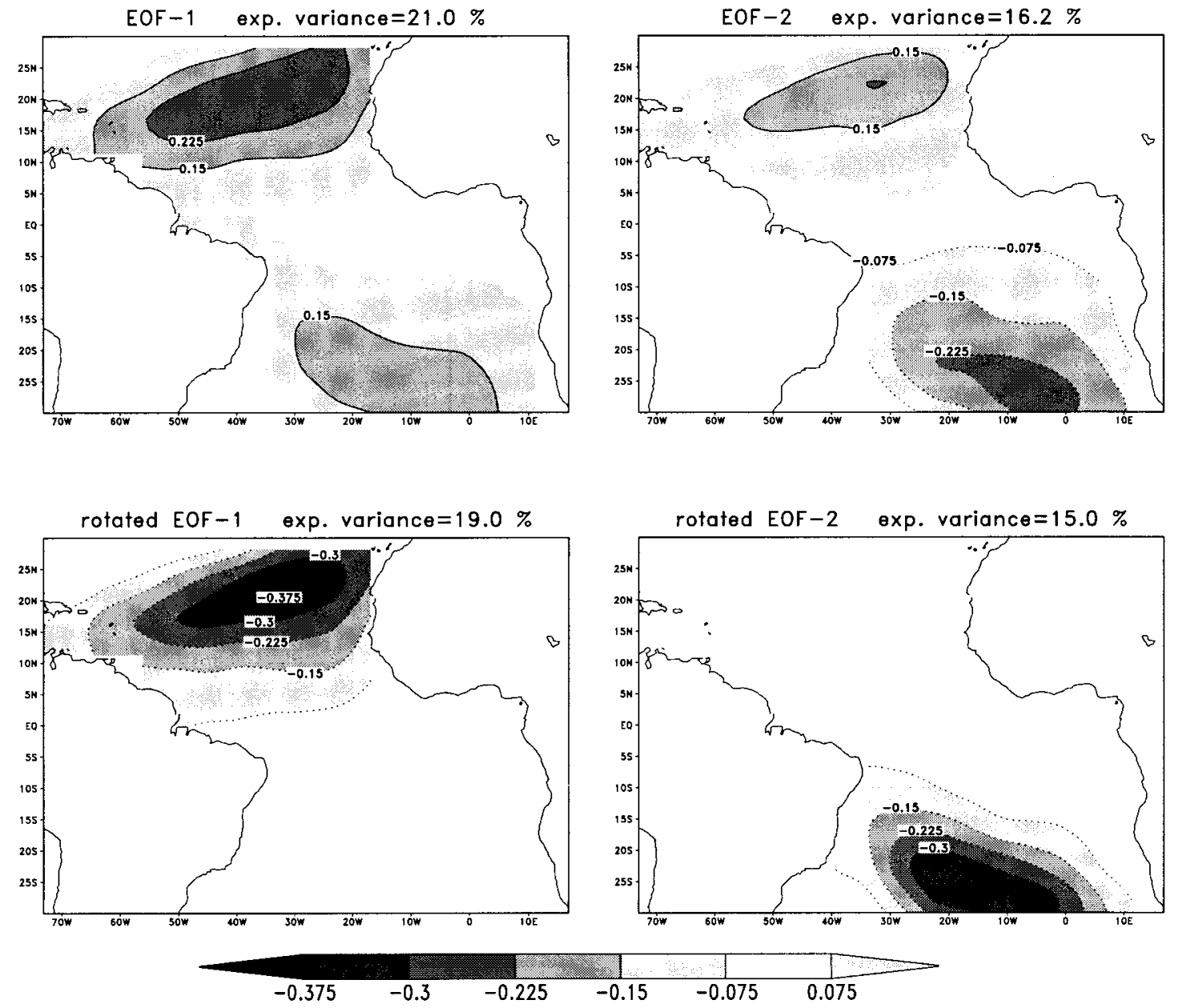

FIG. 10. EOF-1 and -2 from the ECHAM3 mixed layer ocean simulation (upper plots). Lower plots show the VARIMAX rotated EOFs.

SST anomalies and there is no significant interhemispheric response. We therefore conclude from the experiments with the northern and southern SST anomalies that the atmosphere responds locally to the SST anomalies and that SST anomalies in one hemisphere of the tropical Atlantic do not effect the other hemisphere.

The response in the net heat flux is mainly caused by a change in the latent heat flux, while in the center of the SST anomalies the shortwave radiative flux does also contribute to the change in the net heat flux (not shown). The response of the latent heat flux is basically due to the change in the strength of the trade winds that is caused by the warming over the SST anomalies. The mean winds in the two regions with the SST anomalies are easterly with a smaller component toward the equator. Thus the response will lead to a weakening of the wind strength (see Fig. 14).

From these experiments we conclude that the variability in the two centers of the trade winds is mainly driven by variations of the wind field, which will lead to a change in the latent heat loss of the ocean. These results have also been found in several other studies (e.g., Carton et al. 1996; Wagner 1996)

The response of the atmosphere to an anomalous SST dipole (shown on the upper right side of Figs. 13 and 14) can be understood as the superposition of the two single SST experiments with anomalies in the northern and southern trade wind zones. This is indicated by the difference between the dipole experiment and the sum of the experiments with the single northern and the single negative southern SST patterns shown in the lower right-hand side of Figs. 13 and 14. From these experiments it can be concluded that there is no specific atmospheric response to an interhemispheric SST anomaly dipole, which cannot be explained by a superposition of the local responses to the single SST anomaly in the northern or southern trade wind zones independently.

\section{Conclusions}

EOF analyses of annual mean SST from the GISST observations during the period 1903-94 and of four dif- 
rotated EOF-1

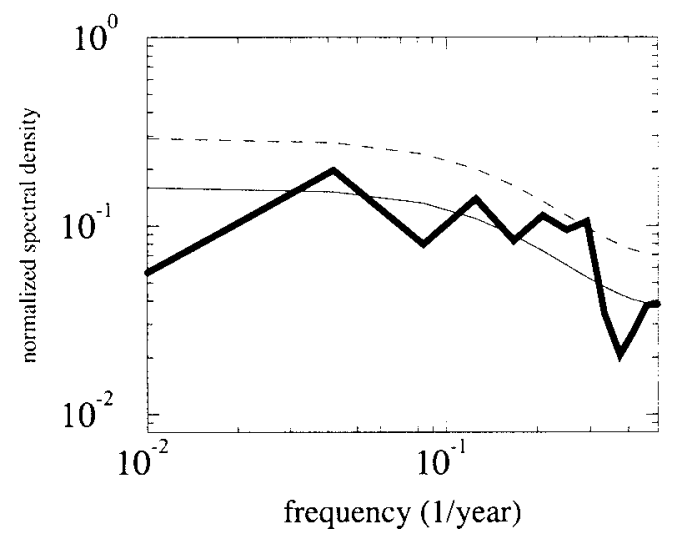

rotated EOF-2

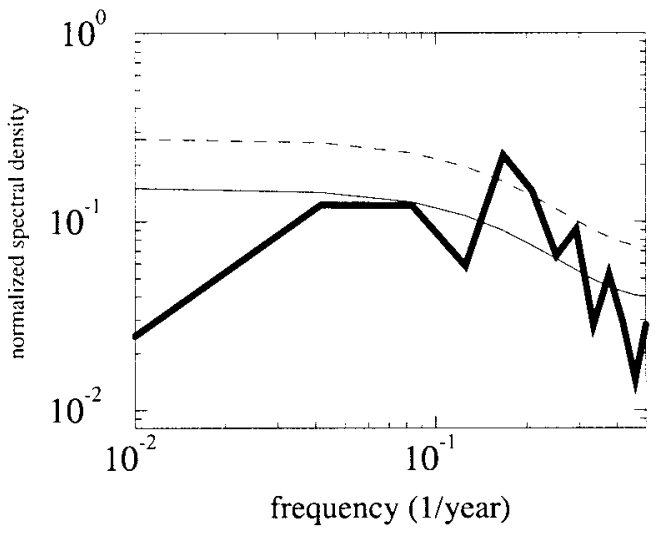

FIG. 11. Spectra of the rotated EOF-1 and -2 from the ECHAM3 mixed layer ocean simulation.

ferent CGCMs simulations show consistent results. The dominant SST variability is well represented by the two leading rotated EOFs for all datasets. The rotation has been calculated with the VARIMAX criterion. In all datasets the two leading rotated EOFs are centered in the two trade wind zones. The correlation between the SST fluctuations in the northern and in the southern trade wind zones is not significantly different from zero. An interhemispheric dipole or stated differently, an anticorrelation of the SSTs in the northern and southern trade wind zones, which could be important for rainfall anomalies in, for example, northeast Brazil, therefore does not exist. We conclude that the dipole pattern is an artifact of the EOF analyses technique used. This has been confirmed by coupled model experiments, by an ocean mixed layer experiment, and by atmospheric response experiments. All of these experiments indicate that ocean dynamics are not important in the generation
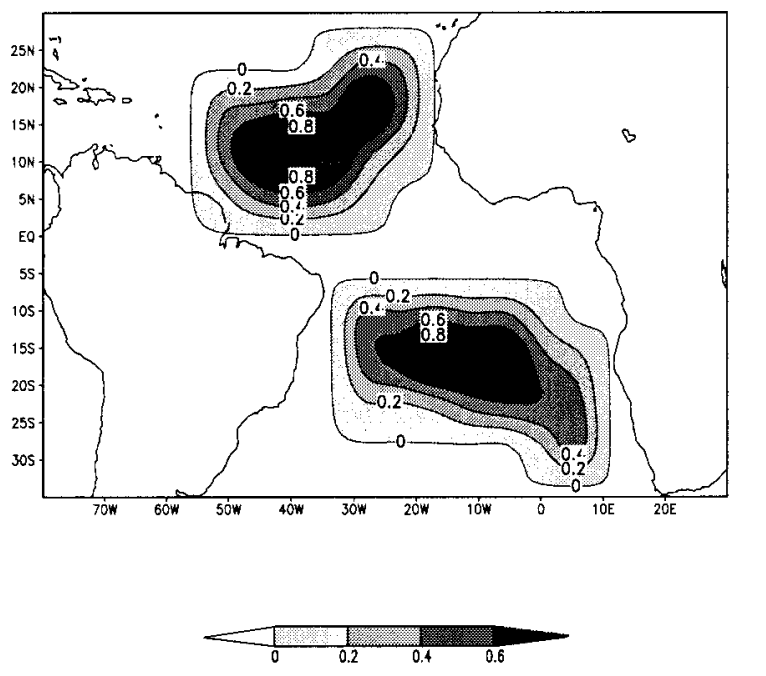

FIG. 12. SST pattern for the atmosphere model simulations. of tropical Atlantic SST anomalies and that SST anomalies are forced by the atmosphere.

The ordinary EOF analysis of the GISST observations does not separate the two patterns centred in the trade wind zones. EOF-1 is an overall monopole and EOF-2 a dipole (see Fig. 1). A rotation of the 10 leading EOFs with the VARIMAX criterion separates the SST variability in the trade wind zones into two patterns with orthogonal time evolution. The explained variances of the EOF-1 and EOF-2 of the GISST observations are comparable over large regions in the tropical Atlantic.

Although the two leading EOFs of the GISST dataset are separated by one standard deviation, the representation with two patterns centered in the trade wind zones is still physically useful. The question whether the two EOFs are statistically degenerated or not is of minor importance for the SST variability in the tropical Atlantic. The fact that EOF-1 and EOF-2 can be represented as two spatially well-separated patterns with orthogonal time evolution is physically more important. Consider EOF-1 as statistically separated from EOF-2, a fact that is almost statistically significant for the GISST observations and for the GFDL simulations, then the two spatially separated patterns from the rotation are not a possible EOF system, but they are still an orthogonal basis of the SST variability in the tropical Atlantic. Thus, the dominance of EOF-1 can be understood as a weak interaction between the two rotated patterns, which leads to the preferential EOF system shown in Fig. 1. This weak connection can have different origins. Due to the fact that in both the GISST observations and in the GFDL simulation EOF-1 has positive correlation coefficients on both hemispheres, a global nonlinear trend can be responsible for the weak connection between the two hemispheres. The influence of the ENSO mode from the Pacific, which is expected to have equal signs in both hemispheres, may also be responsible for the weak connection. The two patterns 

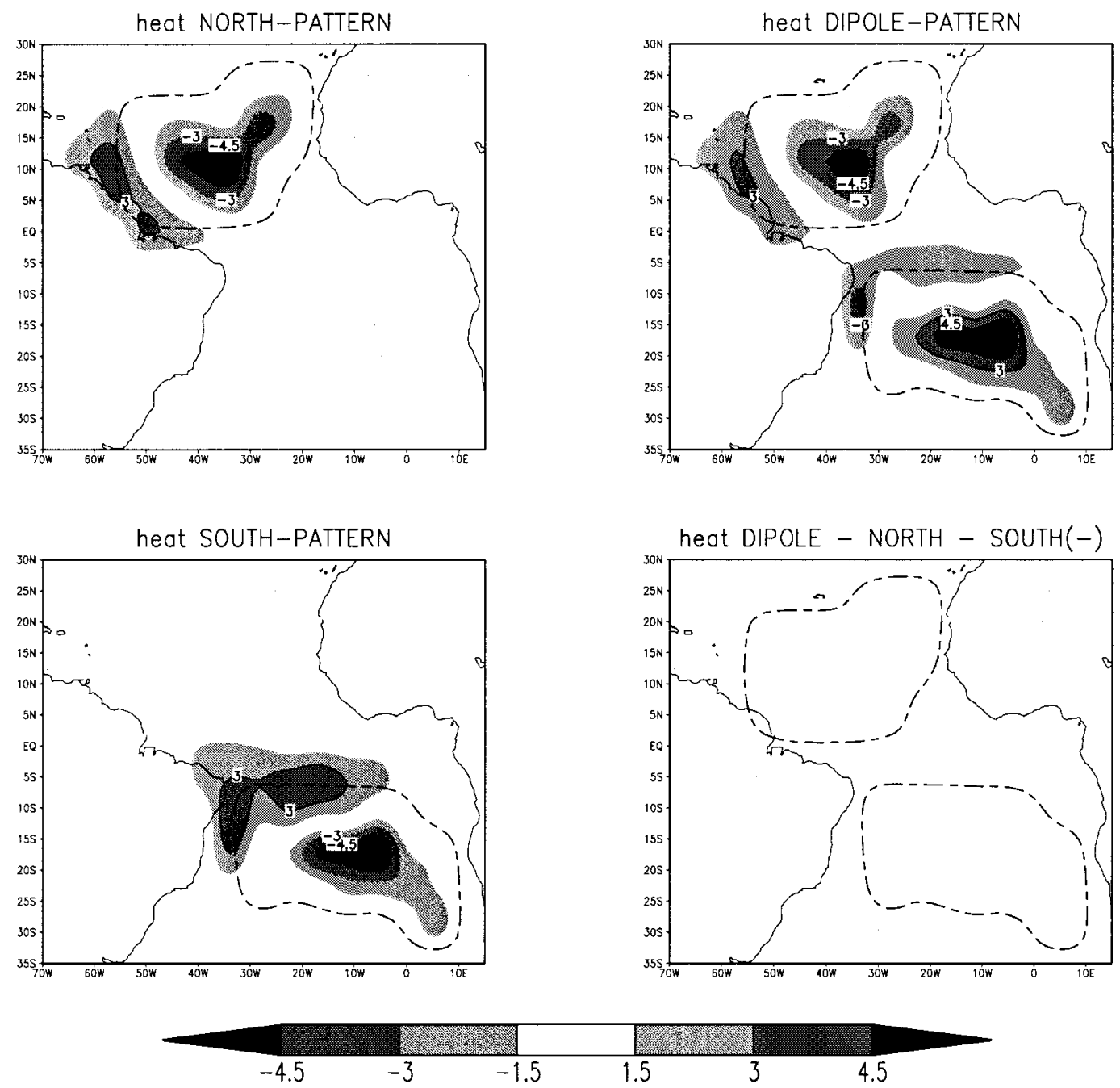

FIG. 13. Results of the atmosphere model simulation, as described in the text. The plots show the difference between the 10 -yr mean of the net heat flux for each simulation and the 20 -yr mean of the net heat flux of the control run divided by the standard deviation of the annual mean values of the $20 \mathrm{yr}$ from the control run. The units are standard deviation. The dashed line indicates the region with the changed SST for each simulation. The lower right plots shows the superposition of three simulation results.

centered in the trade wind zones are not completely spatially separated, but they overlap at the thermal equator and move with the seasonal cycle. Therefore, it is very likely that this connection at the equator leads to a weak interaction between the two patterns.

The SST spectra in both trade wind zones are consistent with the assumption of red noise spectra of the first-order autoregressive [AR(1)] processes. There has been a discussion whether the SST exhibits increased variability at decadal timescales as found by Mehta and Delworth (1995) in the observations and in the GFDL CGCM data. In our analysis we have not found any evidence for significantly enhanced variability at decadal timescales. Although the spectra of the SST in the GFDL data and the observations do show slightly enhanced variance at decadal timescales relative to the estimated spectra of the AR(1) processes, the spectra of the SST are still consistent with those derived from $\mathrm{AR}(1)$ processes, which is in agreement with the later work of these authors (Delworth and Mehta 1998).

The general agreement of the spectral distribution of the SST variability in all analyzed datasets with AR(1) processes and the local structure of the two leading EOFs in all data sets leads us to the conclusion that the ocean is responding passively to the atmospheric forcing by simply integrating the atmospheric noise due to the large heat capacity of the ocean's mixed layer. This is the basic idea of Hasselmann's stochastic climate model. Therefore, ocean dynamics, such as wave propagation, convection, and advection, are not important for producing SST variability in the tropical Atlantic. Atmospheric forcing is the most important process for gen- 

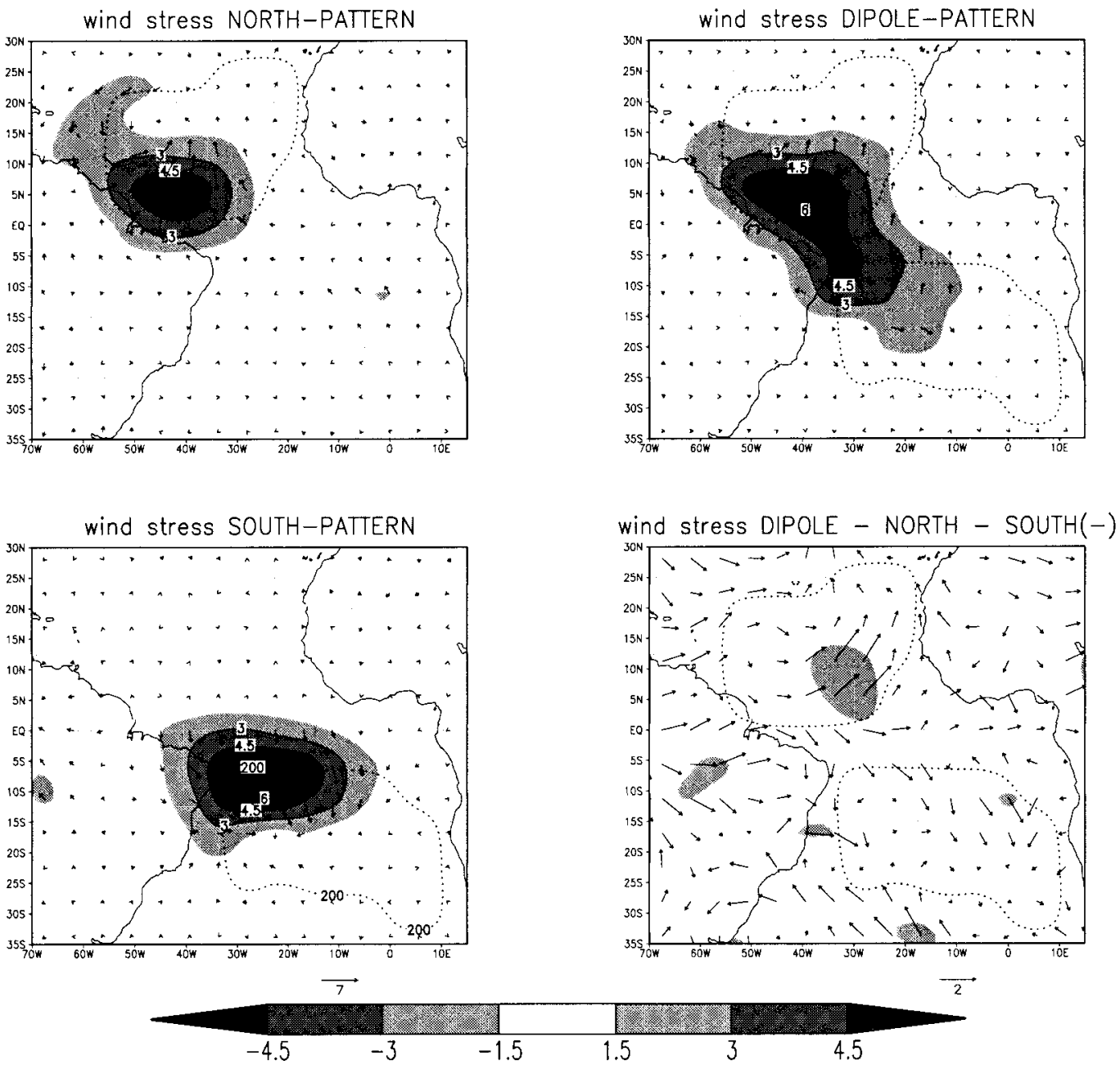

FIG. 14. Results of the atmosphere model simulation, as described in the text. The plots show the vector difference between the 10-yr mean of the wind stress for each simulation and the 20-yr mean of the wind stress of the control run divided by the standard deviation of the annual mean values of the $20 \mathrm{yr}$ from the control run. The units are standard deviation. The dashed line indicates the region with the changed SST anomaly for each simulation. The lower right plots shows the superposition of three simulation results.

erating SST anomalies. We would like to note, however, that this conclusion is restricted to the models analyzed and that we cannot exclude the possibility that all models suffer from serious deficiencies. Furthermore, the SST observations available are rather short to study decadal variability, so that some uncertainty remains.

The relationship between SST, wind stress, and net heat flux anomalies in the tropical Atlantic, as they have been found in analyzing different simulations with an AGCM forced by different SST anomalies, is consistent with this picture. Furthermore, a simple mixed layer ocean model coupled to an AGCM, which produces SST variability that is similar to that simulated by complex ocean-atmosphere general circulation models, supports the idea that the SST variability is only a passive response to the atmospheric forcing and that ocean dy- namics, which are not included in the simple mixed layer ocean model, are not important.

Carton et al. (1996) conducted a series of experiments with an ocean GCM modifying surface forcing to investigated the nature of SST variability in the tropical Atlantic. They found that local wind-induced latent heat loss was the most important term in regulating interannual SST variability away from the equator, which is also consistent with our results. They also found that ocean dynamics was most important at the equator. However, an equatorial pattern does not show up in our analysis. We cannot exclude the possibility that ocean dynamics are important at the equator. Our analysis, however, shows that this kind of ENSO-like variability does not account for a large fraction of the SST variability and does not significantly effect the structure of the dominant SST pattern. 
We did not find any evidence for an interhemispheric coupled ocean-atmosphere mode that would imply increased predictability at decadal timescales as found by Chang et al. (1997). Unfortunately, this limits (if correct) the predictability of the tropical Atlantic SST variability and associated climate fluctuations to that derived from the persistence of the SST anomalies.

In the past, analyses of the Atlantic variability have either concentrated on the Tropics or on the mid- and higher latitudes. This differentiation was done because it was believed that different kinds of physical mechanisms are important in the different regions. The results of our analyses indicate that this is not the case. We found that the SST variability in the two hemispheres of the tropical Atlantic are mainly independent, but that the rotated EOFs that are centered in the northern tropical Atlantic are highly correlated to the first EOF of the SST anomalies in the midlatitudes of the North Atlantic (from $20^{\circ}$ to $60^{\circ} \mathrm{N}$ ) for all datasets. Although we have not investigated the connection of the northern tropical Atlantic to the midlatitudes, the results indicate that the connection may be via the atmospheric teleconnections.

If we finally compare the tropical Atlantic Ocean with the tropical Pacific, we find that in the Pacific the equatorial variability dominates the SST variability of the tropical region, while in the Atlantic the equatorial region does not strongly influence the dominant SST patterns. Although the spectra of the EOF-1 does show some enhanced variance in the interannual timescale (see Fig. 2) the rotation of the EOFs does separate the equatorial region into the two pattern centered in the trade wind zones. Thus the Atlantic and Pacific differ only in the strength of the equatorial SST variability, while the SST variability in the trade wind zones is similar in both oceans.

Acknowledgments. We would like to thank Dr. A. Grötzner for fruitful discussions. Special thanks also to Mrs. M. Esch, Dr. E. Röckner, and Mr. U. Schlese for helping in the implementation of the mixed layer routine in the ECHAM3 atmosphere model. We would also like to thank all the people that have been involved in the production of the CGCM data and the GISST observations. This work was supported by the European Unions SINTEX project and the German government through its Ocean-CLIVAR program.

\section{REFERENCES}

Bacher, A., J. M. Oberhuber, and E. Roeckner, 1998: ENSO dynamics and seasonal cycle in the tropical Pacific as simulated by the ECHAM4/OPYC3 coupled general circulation model. Climate Dyn., 14, 431-450.

Carton, J. A., X. Cao, S. G. Benjamin, and A. M. Da Silva, 1996: Decadal and interannual SST variability in the tropical Atlantic. J. Phys. Oceanogr., 26, 1165-1175.

Chang, P., L. Ji, and H. Li, 1997: A decadal climate variation in the tropical Atlantic Ocean from thermodynamic air-sea interactions. Nature, 385, 516-518.

Delworth, T., and V. M. Mehta, 1998: Simulated interannual to decadal variability in the tropical and sub-tropical North Atlantic. Geophys. Res. Lett., 25, 2825-2828.

Enfield, D. B., and D. A. Mayer, 1997: Tropical Atlantic sea surface temperature variability and its relation to El Nino-Southern Oscillation. J. Geophys. Res., 102, 929-945.

Frey, H., M. Latif, and T. Stockdale, 1997: The coupled GCM ECHO2. Part I: The tropical Pacific. Mon. Wea. Rev., 125, 703-719.

Hasselmann, K., 1976: Stochastic climate models. Part I: Theory. Tellus, 28, 473-485.

Houghton, R. W., and Y. M. Tourre, 1992: Characteristics of lowfrequency sea surface temperature fluctuations in the tropical Atlantic. J. Climate, 5, 765-771.

Huang, B., J. A. Carton, and J. Shukla, 1995: A numerical simulation of the variability in the tropical Atlantic Ocean, 1980-1988. J. Phys. Oceanogr., 25, 835-854.

Kaiser, H. F., 1958: The VARIMAX criterion for analytic rotations in factor analysis. Psychometrika, 23, 187-200.

- 1959: Computer program for the VARIMAX rotation in factor analysis. Edu. Psych. Meas., 19, 413-420.

Latif, M., A. Grötzner, and H. Frey, 1996: El Hermanito: El Niño's overlooked little brother in the Atlantic. MPI Rep. 196, 14 pp. [Available from Max-Planck-Institut für Meteorologie, Bundesstr. 55, 20146 Hamburg, Germany.]

Maier-Reimer, E., U. Mikolajewicz, and K. Hasselmann, 1993: Mean circulation of the Hamburg LSG model and its sensitivity to the thermohaline surface forcing. J. Phys. Oceanogr., 23, 731-757.

Manabe, S., R. J. Stouffer, M. J. Spelman, and K. Bryan, 1991: Transient response of a coupled ocean-atmosphere model to gradual changes of atmospheric CO2. Part I: Annual mean response. J. Climate, 4, 785-818.

Mehta, V. M., 1998: Variability of the tropical ocean surface temperature at decadal-multidecadal time scales. Part I: Atlantic Ocean. J. Climate, 11, 2351-2375.

— lantic ocean surface temperature in shipboard measurements and in a global ocean-atmosphere model. J. Climate, 8, 172-191.

Moura, A. D., and J. Shukla, 1981: On the dynamics in northeast Brazil: Observations, theory and numerical experiments with a general circulation model. J. Atmos. Sci., 38, 2653-2674.

North, G. R., T. L. Bell, R. F. Cahalan, and F. J. Moeng, 1982: Sampling errors in the estimation of empirical orthogonal functions. Mon. Wea. Rev., 110, 699-706.

Parker, D. E., C. K. Folland, A. Bevan, M. N. Ward, M. Jackson, and F. Maskell, 1995: Marine surface data for analysis of climate fluctuations on interannual to century time-scales. Natural Climate Variability on Decadal to Century Time Scales, D. G. Martinson et al. Eds., National Academy Press, 241-250.

Penland, C., and L. Matrosova, 1998: Prediction of tropical Atlantic sea surface temperatures using linear inverse modeling. J. Climate, 11, 483-496.

Richman, M. B., 1986: Review article: Rotation of principal components. J. Climatol., 6, 293-335.

Roeckner, E., and Coauthors, 1992: Simulation of the present-day climate with the ECHAM model: Impact of model physics and resolution. MPI Rep. 93, 171 pp. [Available from Max-PlanckInstitut für Meteorologie, Bundesstr. 55, 20146 Hamburg, Germany.]

, J. M. Oberhuber, A. Bacher, M. Christoph, and I. Kirchner, 1996: ENSO variability and atmospheric response in a global coupled atmosphere-ocean GCM. Climate Dyn., 12, 737-754.

Voss, R., R. Sausen, and U. Cubasch, 1998: Periodically synchronously coupled integrations with the atmosphere-ocean general circulation model ECHAM3/LSG. Climate Dyn., 14, 249-266.

Wagner, R. G., 1996: Mechanisms controlling variability of the interhemispheric sea surface temperature gradient in the tropical Atlantic. J. Climate, 9, 2010-2019.

Zebiak, S. E., 1993: Air-sea interaction in the equatorial Atlantic region. J. Climate, 6, 1567-1586. 